\section{Imbibition by Alkali Sacaton Seeds ${ }^{1}$}

\section{O. D. KNIPE}

Associate Plant Ecologist, Rocky Mountain Forest and Range Experiment Station, ${ }^{2}$ Albuquerque, New Mexico

\section{Highlight}

Alkali sacaton (Sporobolus airoides Torr.) seeds imbibed water rapidly. Large seeds gained $47 \%$ and small seeds gained $71 \%$ of their dry weight within the first $30 \mathrm{~min}$ after wetting. The large seeds had gained $124 \%$ and the small seeds $165 \%$ of their dry weight after $72 \mathrm{hr}$.

The purpose of this study on alkali sacaton (Sporobolus airoides Torr.) was to provide a basis for future studies on (1) the amount of imbibition necessary for germination, for photo effects on germination, and before high temperatures affect germination, and (2) the effect of periodic wetting and drying on germination.

\section{Literature Review}

Water uptake by seeds, the first process of germination, is known as imbibition. The amount of water imbibed is determined by (1) the composition of the secd, (2) thc pcrmcability of the seed coat to water, and (3) the availability of water.

All seeds must imbibe moisture before the germination process can begin (U.S. Dep. Agr., Forest Serv., 1948; Baker, 1950). The amount of imbibi-

\footnotetext{
${ }^{1}$ Received May 25, 1970; accepted for publication July 3, 1970.

${ }^{2}$ Forest Service, U.S. Dept. of Agriculture, with central headquarters maintained at Fort Collins in cooperation with Colorado State University; author is located at Albuquerque, in cooperation with the University of New Mexico. Research reported here was conducted in cooperation with the Bureau of Land Management, U.S. Dept. of the Interior. Extract from dissertation completed in partial fulfillment for the Ph.D. in Range Management, Department of Watershed Management, University of Arizona.
}

tion necessary to initiate germination depends largely upon the species (Larson, 1968). Hunter and Erickson (1952) reported a minimum moisture requirement for germination of 30,26 , 50 , and $31 \%$ for corn, rice, soybeans, and sugar beets, respectively.

Goo (1951) and Asakawa (1956) showed that water uptake by coniferous tree seeds can be divided into three phases: (1) rapid initial uptake, (2) a tapering-off period of slow uptake, and (3) distinctly increased uptake resulting from metabolic activity in germination.

Larson (1968) found that, in a $24-\mathrm{hr}$ period, pea seeds (Pisum sativum L.) submerged in water with seed coats intact and with seed coats removed imbibed 20 and $17 \mathrm{~g}$ of water per 100 seeds, respectively. Pea seeds without coats had a greater initial imbibition rate, but seeds with and without coats soon imbibed water at the same rate. Approximately $85 \%$ of the water was imbibed during the first 5 to $6 \mathrm{hr}$.

No work was found reporting on imbibition by range grass seeds.

\section{Procedures}

Small air-dry samples $(0.50 \mathrm{~g})$ of large and small alkali sacaton seeds were sandwiched between germination blotter papers saturated with distilled water. After the seeds had imbibed for the desircd time, the blotter covering the seeds was removed and the blotter holding the seeds was placed on a dry blotter to eliminate free water. The seeds were then scraped into a weighing vessel and weighed. The percentage of weight change (dry weight basis) was determined at intervals ranging from $5 \mathrm{~min}$ to $72 \mathrm{hr}$ after the start of imbibition. A Mitscherlich curve (Snedecor, 1956) was fitted to the data. Separate $0.50 \mathrm{~g}$ samples were used for each determination.

\section{Results and Discussion}

The large seeds gained $47 \%$ of their dry weight during the first half $\mathrm{hr}$ after the start of imbibition (Fig. 1). They continued to gain weight at a constant, though less rapid, rate through the $4 \mathrm{th} \mathrm{hr}$. The large seeds lost $8 \%$ of their weight during the 5 th hr, and gained only $5 \%$ from the 6 th through the 9 th hr. Thereafter, they gained steadily to $118 \%$ of their original weight after $36 \mathrm{hr}$. Some of this gain was due to weight gains by the developing seedlings, as sprouting began during the 28th hr. The weight increase from the 36 th through the $72 \mathrm{nd} \mathrm{hr}$ was only $8 \%$. There were no unusual weight changes associated with the appearance of sprouts.

The weight of the small seeds increased more rapidly, and their final percentage increase in weight was greater than that of the large seeds (Fig. 1). The small seeds gained $71 \%$ of their original weight during the first half hr after the start of imbibition, and had doubled their weight after $4 \mathrm{hr}$. The small seeds did not lose weight during the 5 th $\mathrm{hr}$ as did the large seeds, but their rate of gain decreased during the 5 th and 6 th $\mathrm{hr}$. This period of slow gain corresponded to the period during which the large seeds lost (5th $\mathrm{hr}$ ) and gained only slightly (6th to 9 th $\mathrm{hr}$ ) in weight. As with the large seeds, the weight of the small seeds increased from the 10th through the 36 th hr. From 36 through $72 \mathrm{hr}$ the weight gain of the small seeds was $25 \%$.

Sprouts from the small seeds were first visible during the 32nd hr. There were no unusual weight changes associated with the appearance of sprouts; weight changes after the 32nd hr were due to weight changes of the developing seedlings, however, and not to imbibition by the seeds.

Changes in weight of both large and small seeds during the 5 th and 6 th $\mathrm{hr}$ may be due, at least in part, to solvation of the seed coat and exudation losses. A mucilaginous substance was present on the blotters after seeds had imbibed for more than an hr were removed. Microscopic examination revealed that the outer portion of the seed coat of alkali sacaton is transformed to mucilage upon wetting (Figs. 2 and 3). Also, a brown exudate was present on the blotters after the seeds had imbibed for more than $2 \mathrm{hr}$; the extent of staining increased through the 7 th $\mathrm{hr}$, then remained constant. Exudation losses appeared to be slightly greater from the large seeds, which probably accounts for a part 


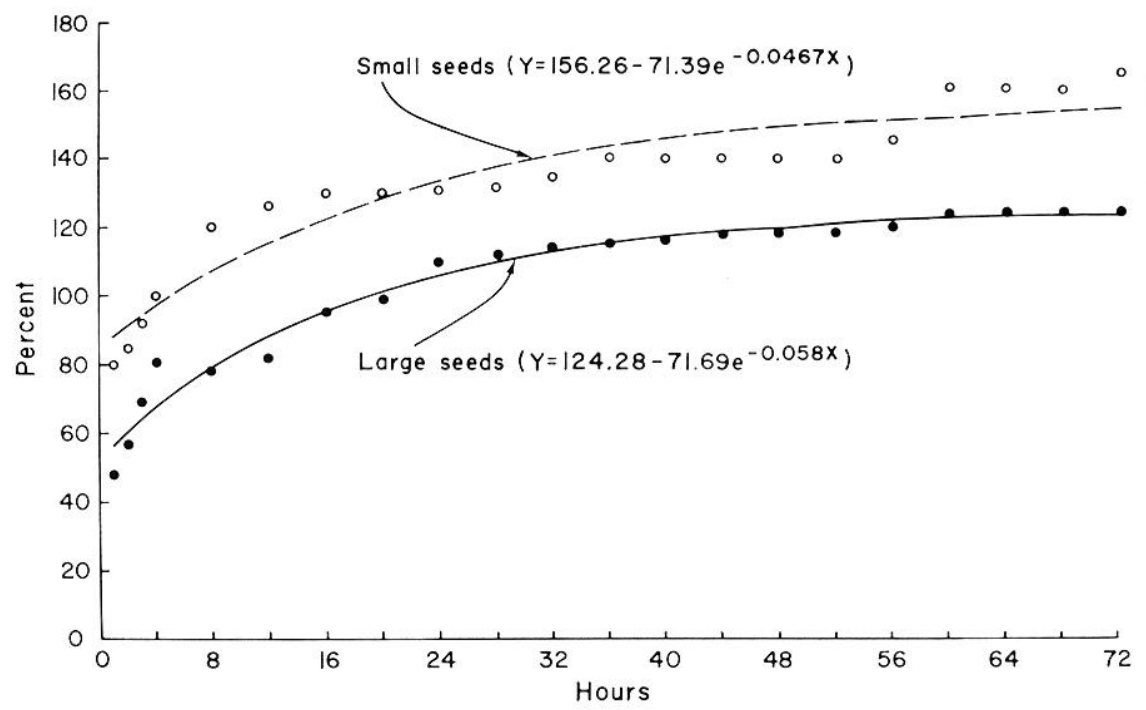

Fig. 1. Percentage of imbibition (dry-weight basis) by large and small alkali sacaton seeds, in relation to number of hours after start of imbibition.

of their loss in weight during the 5 th hr after the start of imbibition.

It was initially reasoned that the large seeds lost more mucilage than the small seeds, and that this loss occurred on about the 6th $\mathrm{hr}$ after the start of imbibition. Microscopic examination revealed that this theory is not necessarily true, however, because (1) the amount of mucilage surrounding the seeds was approximately inversely proportional to seed size (Fig. 2 ), and (2) the mucilage did not separate from the seed at any specific time after the start of imbibition; in fact, the mucilage did not separate from the seeds at all unless it was removed by some mechanical means. It should be noted, however, that the mucilage can be separated from a seed that has imbibed for about one hr by merely touching the seed or swirling it about in water.

The mucilage appears as a film about the seed immediately after the seed is wetted, and the thickness of the film increases for several hr thereafter (Fig. 3). Thus it is not clear why the large seeds lost weight during the 5 th $\mathrm{hr}$ after the start of imbibition. If the decrease had been due to loss of mucilage, the loss from the small seeds would have been greater because the amount of mucilage in proportion to the remainder of the seed is greater. Weight loss apparently was due primarily to a greater exudation loss by the larger seeds. Large seeds have a greater percentage of endosperm and thus a greater percentage

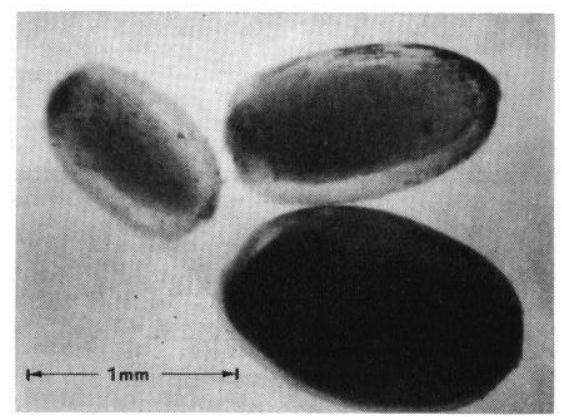

FIG. 2. Large, medium and small alkali sacaton seeds after $2 \mathrm{hr}$ imbibition: note that the thickness of the mucilaginous membrane is inversely proportional to seed size.

were placed in thermos bottles and wetted, a thermometer was inserted into the seeds, and the mouth of the thermos sealed with cotton. The test was replicated twice for both large and small seeds. The premise was that, if the loss in weight was due to respiratory losses, the temperature would rise considerably on about the 4 th $\mathrm{hr}$ (the time corresponding to the period of loss in weight of large seeds during

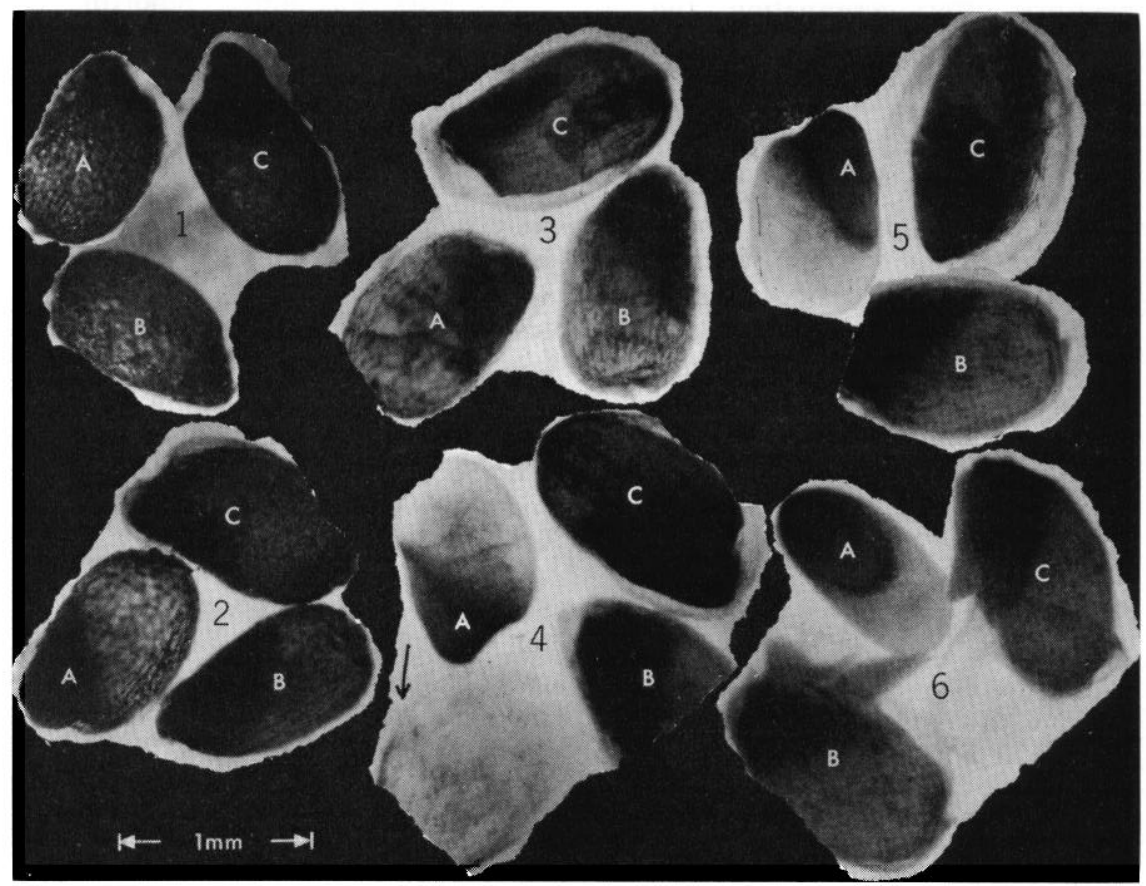

FIG. 3. The appearance of alkali sacaton seeds from prior to the start of imbibition until shortly after germination. All seeds are floating in distilled water. 1-seeds dry; 2-after $5 \mathrm{~min}$ imbibition; 3-after $1 \mathrm{hr}$ imbibition; 4-after $5 \mathrm{hr}$ imbibition (the mucilaginous membrane was removed by simply swirling the water beside the seed with the point of a dissecting needle); 5-after $24 \mathrm{hr}$ imbibition; 6-after $48 \mathrm{hr}$ imbibition, and $1 \mathrm{hr}$ after visible signs of germination appeared (note that the mucilage has begun to separate from seed $\mathrm{C}$, apparently due to the action of the radicle and plumule emerging from the seed). 
imbibition). The test did not verify this premise; the only appreciable temperature change occurred during the first $30 \mathrm{~min}$.

After $72 \mathrm{hr}$ the large seeds had gained $124 \%$ and the small seeds $165 \%$ of their original weight. The difference in amount of apparent imbibition gain may be because the small seeds contain a greater proportion of mucilage. This mucilage is highly absorbent, and as a consequence, the small seeds imbibed a higher percentage of water.

\section{Conclusions}

In this study, imbibition of water by alkali sacaton seeds progressed through three phases: (1) an initial period of rapid uptake lasting for approximately $4 \mathrm{hr}$, (2) a tapering-off period of slow or negative uptake (the large seeds actually lost weight during this period) that lasted approximately $7 \mathrm{hr}$ in the large seeds and $2 \mathrm{hr}$ in the small seeds, and (3) a period of gradual increase that lasted until sprouting became evident: the $28 \mathrm{th} \mathrm{hr}$ in large seeds and the $32 \mathrm{nd} \mathrm{hr}$ in small seeds.

The second stage apparently was due to exudation loss and possibly some loss of the mucilaginous membrane which envelops the seeds. The smaller seeds contained a higher proportion of the highly absorbent mucilage, and thus imbibed more moisture and at a higher rate than the large seeds.

\section{Literature Cited}

Asakawa, S. 1956. On the water absorption by Pinus koraiensis seeds. Forest. Abstr. 19:1503.
BAKER, F. S. 1950. Principles of silviculture. McGraw-Hill Book Co., Inc., New York.

Goo, M. 1951. Water absorption by tree seeds (during germination). Forest. Abstr. 13:1049.

Hunter, J. R., and A. E. Erickson. 1952. Relation of seed germination to soil moisture tension. Agron. J. 44:107-109.

Larson, L. A. 1968. The effect soaking pea seeds with or without seed coats has on seedling growth. Plant Physiol. 43:255-259.

SNEDECOR, G. W. 1956. Statistical methods. Iowa State College Press, Ames, Iowa, Ed. 5, p. 452.

United States Dep. of Agr., Forest SERv. 1948. Woody plant seed manual. Misc. Pub. 654. 416 p. 